\title{
Efficacy of a novel topical combination of esafoxolaner, eprinomectin and praziquantel in cats against Toxocara cati and Dipylidium caninum
}

\author{
Martin Knaus ${ }^{1, *}$, Christine Baker ${ }^{2}$, Roberto Alva ${ }^{2}$, Elizabeth Mitchell ${ }^{2}$, Jennifer Irwin ${ }^{2}$, Enstela Shukullari ${ }^{3}$, \\ Abdullah Veliu ${ }^{4}$, Froylán Ibarra-Velarde ${ }^{5}$, Julian Liebenberg ${ }^{6}$, Craig Reinemeyer ${ }^{7}$, Eric Tielemans ${ }^{8}$, \\ Kenneth Wakeland ${ }^{9}$, and Chris Johnson ${ }^{9}$ \\ ${ }^{1}$ Boehringer Ingelheim Vetmedica GmbH, Kathrinenhof Research Center, Walchenseestr. 8-12, 83101 Rohrdorf, Germany \\ 2 Boehringer Ingelheim Animal Health, 1730 Olympic Drive, Athens, GA 30601, USA \\ ${ }^{3}$ Faculty of Veterinary Medicine, Agricultural University of Tirana, Rruga Paisi Vodica 1025, Tirana, Albania \\ ${ }^{4}$ Center for Animal Services, Fond. Prosp. Integr., Rr. Mine Peza, Pall. 3, Shk. 1/4, 1000 Tirana, Albania \\ ${ }^{5}$ Universidad Nacional Autónoma de México, Ciudad Universitaria, Coyoacan 04510, Mexico \\ ${ }^{6}$ Clinvet International (Pty) Ltd., P.O. Box 11186, Universitas, Bloemfontein 9321, Republic of South Africa \\ ${ }^{7}$ East Tennessee Clinical Research, 80 Copper Ridge Farm Rd, Rockwood, TN 37854, USA \\ ${ }^{8}$ Boehringer-Ingelheim Animal Health, 29 Avenue Tony Garnier, 69007 Lyon, France \\ ${ }^{9}$ Boehringer-Ingelheim Animal Health, 3239 Satellite Blvd, Duluth, GA 30096, USA
}

Received 2 November 2020, Accepted 8 March 2021, Published online 2 April 2021

\begin{abstract}
NexGard ${ }^{\circledR}$ Combo, a novel topical antiparasitic product for cats, combines the insecticide/acaricide esafoxolaner with the nematocide eprinomectin and cestodicide praziquantel. The efficacy of this combination product was evaluated against two common endoparasites of global occurrence in cats, the nematode Toxocara cati and the cestode Dipylidium caninum, in five controlled studies using naturally or experimentally infected cats with parasites of North American, South African or European origin. Cats evaluated in these studies harbored patent infection of the target parasite confirmed through a pre-treatment fecal examination. In each study, cats were allocated randomly to two groups of equal size ( 8 or 10 cats per group per study), one group treated with a placebo (mineral oil) and the other with NexGard ${ }^{\circledR}$ Combo. Both treatments were administered once as a spot-on at $0.12 \mathrm{~mL}$ per kg body weight to deliver the minimum label dosage (1.44 mg/kg esafoxolaner, $0.48 \mathrm{mg} / \mathrm{kg}$ eprinomectin, and $10.0 \mathrm{mg} / \mathrm{kg}$ praziquantel) to the NexGard ${ }^{\circledR}$ Combo-treated cats. To determine efficacy, geometric mean parasite counts seven to 12 days after treatment of placebo-treated (control) cats and NexGard ${ }^{\circledR}$ Combo-treated cats were compared. The efficacy of NexGard $^{\circledR}$ Combo was $98.8 \%$ and $100 \%$ against adult T. cati in two studies; and $98.0 \%, 98.3 \%$ and $93.2 \%$ against D. caninum in three studies. No adverse events related to treatment were observed throughout the studies. These studies demonstrate high efficacy against these major feline endoparasites and excellent acceptability of the novel topical antiparasitic combination of esafoxolaner, eprinomectin and praziquantel.
\end{abstract}

Key words: Cat, Intestinal helminth, Esafoxolaner, Eprinomectin, Praziquantel, Efficacy.

Résumé - Efficacité d'une nouvelle association topique d'esafoxolaner, d'éprinomectine et de praziquantel chez le chat contre Toxocara cati et Dipylidium caninum. NexGard ${ }^{\circledR}$ Combo, un nouveau produit antiparasitaire topique pour chats combine l'insecticide/acaricide esafoxolaner avec le nématocide éprinomectine et le cestodicide praziquantel. L'efficacité de ce produit d'association a été évaluée contre deux endoparasites communs d'occurrence mondiale chez le chat, le nématode Toxocara cati et le cestode Dipylidium caninum, dans cinq études contrôlées utilisant des chats naturellement ou expérimentalement infectés par des parasites d'origine nord-américaine, sud-africaine ou européenne. Les chats évalués dans ces études présentaient une infection patente du parasite cible confirmée par un examen fécal avant le traitement. Dans chaque étude, les chats ont été répartis au hasard en deux groupes de taille égale (8 ou 10 chats par groupe et par étude), un groupe traité avec un placebo (huile minérale) et

*Corresponding author: martin. knaus@boehringer-ingelheim.com

Special Issue - NexGard ${ }^{\circledR}$ Combo (esafoxolaner, eprinomectin, praziquantel): A new endectocide spot-on formulation for cats. Invited Editor: Frédéric Beugnet

This is an Open Access article distributed under the terms of the Creative Commons Attribution License (https://creativecommons.org/licenses/by/4.0), which permits unrestricted use, distribution, and reproduction in any medium, provided the original work is properly cited. 


\begin{abstract}
l'autre avec NexGard ${ }^{\circledR}$ Combo. Les deux traitements ont été administrés une fois par spot-on à $0,12 \mathrm{~mL}$ par kg de poids corporel pour délivrer la dose minimale indiquée sur l'étiquette $(1,44 \mathrm{mg} / \mathrm{kg}$ d'esafoxolaner, $0,48 \mathrm{mg} / \mathrm{kg}$ d'éprinomectine et $10,0 \mathrm{mg} / \mathrm{kg}$ de praziquantel) pour les chats du groupe traité par NexGard ${ }^{\circledR}$ Combo. Pour déterminer l'efficacité, les nombres moyens géométriques de parasites sept à 12 jours après le traitement des chats traités par placebo (témoins) et des chats traités par NexGard ${ }^{\circledR}$ Combo ont été comparés. L'efficacité de NexGard ${ }^{\circledR}$ Combo était de $98,8 \%$ et de $100 \%$ contre $T$. cati adulte dans deux études, et de 98,0\%, 98,3\% et 93,2\% contre D. caninum dans trois études. Aucun événement indésirable lié au traitement n'a été observé tout au long des études. Ces études démontrent la grande efficacité contre ces principaux endoparasites félins et l'excellente acceptabilité de la nouvelle combinaison antiparasitaire topique d'esafoxolaner, d'éprinomectine et de praziquantel.
\end{abstract}

\section{Introduction}

Domestic cats may harbor a wide range of intestinal parasites, such as nematodes, cestodes, trematodes and protozoans [5]. The prevalence of intestinal helminths in domestic cats is variable and depends on several factors such as the cat's age, its habitat (e.g., urban, rural), lifestyle habits (e.g., outdoor access, stray, shelter, domestic pet), and most fundamentally, its predatory behavior [2, 7, 28, 29, 34, 36, 39]. Toxocara cati is the most common nematode and the main ascarid species found in cats, with a high prevalence in kittens, while Toxascaris leonina and hookworms, such as Ancylostoma tubaeforme, Ancylostoma braziliense and Ancylostoma ceylanicum are more rarely diagnosed in domestic cats [5]. Major cestodes of domestic cats are dipylidiid cestodes such as Dipylidium caninum, Joyeuxiella spp. and Diplopylidium spp., and taeniid cestodes such as Taenia taeniaeformis and Echinococcus multilocularis [5].

Some of these helminths are also well known for the zoonotic risk to humans cohabiting with or exposed to infected cats. For example, $T$. cati may cause larva migrans in children as a result of oral ingestion of infective eggs [9, 10, 12, 17], and D. caninum may cause intestinal disorders in humans following flea ingestion [14, 18].

An effective deworming program is essential to control environmental contamination, thereby mitigating clinical implications in infected cats and minimizing the risk of spread and transmission to other felines and to people $[11,35]$.

NexGard ${ }^{\circledR}$ Combo, a novel topical endectoparasiticide formulation for cats combines esafoxolaner, an isoxazoline with insecticidal and acaricidal activity, with two anthelminitic compounds of well-known efficacy, eprinomectin and praziquantel [8, 19-22, 32].

They have become standard therapeutics, as they have been proven safe and highly efficacious against a broad spectrum of intestinal helminths in cats [19-22, 32, 33, 35]. The marketed feline topical products Broadline ${ }^{\mathrm{TM}}$ and Centragard ${ }^{\mathrm{TM}}$ deliver the same dosage of eprinomectin and praziquantel as NexGard ${ }^{\circledR}$ Combo, resulting in similar eprinomectin and praziquantel plasma profiles [16].

The studies reported here were conducted to confirm the efficacy and acceptability of this novel topical product in cats against naturally acquired and experimentally induced infections with $T$. cati or $D$. caninum, as per the requirements of regulatory agencies.

\section{Materials and methods Ethics}

The study protocols were reviewed and approved by the Sponsor's Institutional Animal Care and Use Committee and the studies were conducted according to local animal welfare legislation. Cats were handled with due regard for their wellbeing.

\section{Study design and study animals}

The design of the studies was in accordance with the International Cooperation on Harmonisation of Technical Requirements for Registration of Veterinary Medicinal Products VICH GL7, "Efficacy of Anthelmintics: General Requirements" [37] and VICH GL20 "Efficacy of Anthelmintics: Specific Recommendations for Felines" [38], and the "World Association for the Advancement of Veterinary Parasitology (WAAVP) guidelines for evaluating the efficacy of anthelmintics for dogs and cats" [15]. All studies were conducted according to the principles of VICH GL9 entitled Good Clinical Practice. Personnel involved with the evaluation of efficacy and acceptability were unaware of the treatment assignments.

All studies used a randomized design for allocation of the cats to two groups, NexGard ${ }^{\circledR}$ Combo-treated or placebotreated (control). A total of 96 Domestic Short-hair cats, weighing between 1.0 and $5.0 \mathrm{~kg}$ prior to treatment, aged 3 months to 9 years and owned by the respective contract research organization were included in the studies. The studies were conducted in the United States (Study 1), Albania (Studies 2 and 4), South Africa (Study 3), and Mexico (Study 5). The animals were acclimated to the study facilities for at least seven days prior to treatment administration and cats were housed individually during the entire study duration. The environmental conditions were the same for all animals within a study. Study specific Information such as animal details, allocation, and target parasites are summarized in Table 1.

Purpose-bred cats negative for patent infections with intestinal helminths were included in the two studies using experimentally induced infections (Studies 1 and 3). Study 1 cats were inoculated orally with approximately 34 larvated T. cati eggs daily from the same bulk solution on three consecutive days (63, 62 and 61 days before treatment). The parasite isolate originated from Tennessee, USA. The inoculation schedule was designed so that $T$. cati would be mature adult worms at 
Table 1. Study-specific information: animal details, allocation, and target parasites.

\begin{tabular}{|c|c|c|c|c|c|}
\hline & Study 1 & Study 2 & Study 3 & Study 4 & Study 5 \\
\hline $\begin{array}{l}\text { Target } \\
\text { parasite } \\
\text { (origin) }\end{array}$ & $\begin{array}{c}\text { Toxocara cati } \\
\text { (Tennessee, } \\
\text { USA) }\end{array}$ & $\begin{array}{c}\text { Toxocara } \\
\text { cati } \\
\text { (Albania) }\end{array}$ & $\begin{array}{c}\text { Dipylidium } \\
\text { caninum } \\
\text { (South Africa) }\end{array}$ & $\begin{array}{l}\text { Dipylidium } \\
\text { caninum } \\
\text { (Albania) }\end{array}$ & $\begin{array}{l}\text { Dipylidium } \\
\text { caninum } \\
\text { (Mexico) }\end{array}$ \\
\hline Infection & Induced & Natural & Induced & Natural & Natural \\
\hline Age of cats & 19-21 weeks & $5-8$ months & $1-9$ years & $2-4$ years & 3 months to 3 years \\
\hline ts, range $(\mathrm{kg})$ & $2.0-2.9$ & $1.0-2.1$ & $2.5-4.6$ & $1.2-3.6$ & $1.3-5.0$ \\
\hline Number of cats per group & 10 & 10 & 8 & 10 & 10 \\
\hline Allocation of cats to treatment groups & $\begin{array}{l}\text { Completely } \\
\text { at random }\end{array}$ & $\begin{array}{c}\text { At random after } \\
\text { blocking by } \\
\text { bodyweight }\end{array}$ & $\begin{array}{c}\text { At random after } \\
\text { blocking by } \\
\text { bodyweight }\end{array}$ & $\begin{array}{c}\text { At random after } \\
\text { blocking by } \\
\text { bodyweight }\end{array}$ & $\begin{array}{c}\text { At random after } \\
\text { blocking by } \\
\text { bodyweight }\end{array}$ \\
\hline Timing of parasite recovery after treatment & 7 days & $7 / 8$ days & 7 days & $10 / 11$ days & 10-12 days \\
\hline
\end{tabular}

Table 2. Results of pre-treatment fecal examinations.

\begin{tabular}{|c|c|c|c|c|c|}
\hline & Study 1 & Study 2 & Study 3 & Study 4 & Study 5 \\
\hline Target parasite & Toxocara cati & Toxocara cati & Dipylidium caninum & Dipylidium caninum & Dipylidium caninum \\
\hline Type of Infection & Induced & Natural & Induced & Natural & Natural \\
\hline \multicolumn{6}{|l|}{ Toxocara eggs $^{\mathrm{a}}$} \\
\hline Placebo (control) ${ }^{1}$ & $\begin{array}{c}10 / 10 \\
(899-1944)\end{array}$ & $\begin{array}{c}10 / 10 \\
(500-5800)\end{array}$ & $\begin{array}{l}- \\
-\end{array}$ & $\begin{array}{c}8 / 10 \\
(200-6350)\end{array}$ & $\begin{array}{c}7 / 10 \\
(350-4100)\end{array}$ \\
\hline Treated $^{2}$ & $\begin{array}{c}10 / 10 \\
(904-2292)\end{array}$ & $\begin{array}{c}10 / 10 \\
(100-5200)\end{array}$ & $\begin{array}{l}- \\
-\end{array}$ & $\begin{array}{c}4 / 10 \\
(300-1550)\end{array}$ & $\begin{array}{c}5 / 10 \\
(400-6300)\end{array}$ \\
\hline \multicolumn{6}{|l|}{ Hookworm eggs $^{\mathrm{a}}$} \\
\hline Placebo (control) & - & $\begin{array}{c}0 / 10 \\
-\end{array}$ & - & $\begin{array}{c}3 / 10 \\
(50-200)\end{array}$ & $\begin{array}{c}0 / 10 \\
-\end{array}$ \\
\hline Treated & - & $\begin{array}{c}2 / 10 \\
(0-1150)\end{array}$ & $\begin{array}{l}- \\
-\end{array}$ & $\begin{array}{c}0 / 10 \\
-\end{array}$ & $\begin{array}{c}1 / 10 \\
(300)\end{array}$ \\
\hline \multicolumn{6}{|c|}{ Dipylidiid eggs/proglottids ${ }^{b}$} \\
\hline Placebo (control) & - & $0 / 10$ & $8 / 8$ & $10 / 10$ & $10 / 10$ \\
\hline Treated & - & $0 / 10$ & $8 / 8$ & $10 / 10$ & $10 / 10$ \\
\hline
\end{tabular}

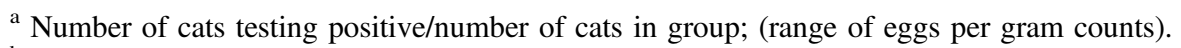

${ }^{\mathrm{b}}$ Number of cats testing positive/number of cats in group.

${ }^{1}$ Mineral oil at $0.12 \mathrm{~mL}$ per kg bodyweight spot-on, once.

${ }^{2}$ NexGard ${ }^{\circledR}$ Combo at $0.12 \mathrm{~mL}$ per kg bodyweight spot-on, once.

the time of treatment. For Study 3, cats were experimentally infected with D. caninum, as described previously [3, 13], and monitored until patent infections were confirmed. The D. caninum isolate originated from a cat in South Africa.

Three studies involved naturally infected animals (Studies 2, 4 and 5) and used locally sourced cats that were selected based on positive fecal examination for the target parasite.

\section{Pre-treatment fecal examination}

For all studies, the selection criterion for inclusion of cats was the presence of patent infection with the target parasite by examination of fecal samples collected within 9 days prior to the day of treatment, and all cats included were confirmed positive for at least fecal stages of the target parasite (Table 2). Fecal samples were examined macroscopically for the presence of cestode segments. In addition, feces were tested for helminth eggs using quantitative flotation techniques (Study 1, modified Wisconsin technique; Studies 2, 4 and 5, modified McMaster techniques).

\section{Treatment administration}

All cats were treated once on Day 0. Cats assigned to the placebo (control) group were administered mineral oil topically at $0.12 \mathrm{~mL}$ per $\mathrm{kg}$ bodyweight. Cats assigned to the NexGard ${ }^{\circledR}$ Combo (esafoxolaner $1.2 \% \mathrm{w} / \mathrm{v}$, eprinomectin $0.4 \% \mathrm{w} / \mathrm{v}$, praziquantel $8.3 \% \mathrm{w} / \mathrm{v}$ ) group received a topical (spot-on) application of the formulation at the minimum recommended dosage of $0.12 \mathrm{~mL} / \mathrm{kg}$ body weight, delivering $1.44 \mathrm{mg}$ esafoxolaner, $0.48 \mathrm{mg}$ eprinomectin, and $10.0 \mathrm{mg}$ praziquantel per $\mathrm{kg}$ body weight. The treatment was applied directly on the skin, after parting the hair, in one spot in the midline of the neck between the base of the skull and the shoulder blades.

\section{Helminth recovery and count}

Animals were humanely euthanized following AVMP Guidelines [1] and necropsied 7-12 days after treatment administration for parasite recovery and count. The contents of the whole gastrointestinal tract (stomach, small and large intestines) 
Table 3. Parasite counts and efficacy.

\begin{tabular}{|c|c|c|c|c|c|}
\hline Parasite & Study/treatment groups & $\begin{array}{l}\text { Number of positive cats/ } \\
\text { number of cats in group }\end{array}$ & $\begin{array}{c}\text { Geometric mean } \\
\text { parasite count (range) }\end{array}$ & Efficacy $^{1}(\%)$ & $p$-value ${ }^{2}$ \\
\hline \multirow[t]{6}{*}{ Adult Toxocara cati } & \multicolumn{5}{|c|}{ Study 1, induced infection (Tennessee, USA) } \\
\hline & Placebo (control) ${ }^{3}$ & $10 / 10$ & $29.5(14-57)$ & 100 & $<0.0001$ \\
\hline & Treated $^{4}$ & $0 / 10$ & 0 & & \\
\hline & \multicolumn{5}{|c|}{ Study 2, natural infection (Albania) } \\
\hline & Placebo (control) & $10 / 10$ & $12.1(2-32)$ & 98.8 & $<0.0001$ \\
\hline & Treated & $1 / 10$ & $0.1(0-3)$ & & \\
\hline \multirow[t]{9}{*}{ Dipylidium caninum } & \multicolumn{5}{|c|}{ Study 3 , induced infection (South Africa) } \\
\hline & Placebo (control) & $7 / 8$ & $28.9(8-267)$ & 98.0 & 0.0018 \\
\hline & Treated & $2 / 8$ & $0.6(3-9)$ & & \\
\hline & \multicolumn{5}{|c|}{ Study 4, natural infection (Albania) } \\
\hline & Placebo (control) & $9 / 10$ & $23.1(3-143)$ & 98.3 & 0.0001 \\
\hline & Treated & $2 / 10$ & $0.4(1-12)$ & & \\
\hline & \multicolumn{5}{|c|}{ Study 5, natural infection (Mexico) } \\
\hline & Placebo (control) & $7 / 10$ & $5.6(1-370)$ & 93.2 & 0.0052 \\
\hline & Treated & $1 / 10$ & $0.4(24)$ & & \\
\hline
\end{tabular}

${ }^{1}$ Percent efficacy $=100[(C-T) / C]$, where $C$ was the geometric mean among placebo controls and $T$ was the geometric mean among the treated animals.

${ }^{2}$ Two-sided probability value from analysis of variance on log-counts of the treated group and the placebo control group.

${ }^{3}$ Mineral oil at $0.12 \mathrm{~mL}$ per $\mathrm{kg}$ bodyweight spot-on, once.

${ }^{4} \mathrm{NexGard}{ }^{\circledR}$ Combo at $0.12 \mathrm{~mL}$ per kg bodyweight spot-on, once.

including scraped mucosa were washed over appropriately sized sieves to remove debris, and examined for helminths. Worm counts were made on total gastrointestinal contents. Helminths were identified to species/genus, and stage, as appropriate, according to their morphology. The number of scolices was counted for cestode numeration.

\section{Acceptability of treatment and health}

Health observations were conducted daily throughout the studies by qualified personnel and at hourly intervals for $4 \mathrm{~h}$ after treatment to detect any health abnormalities.

\section{Statistical analysis}

For each study, target parasite counts were transformed to the natural logarithm of (count +1$)$ for calculation of geometric means for the treatment group. Efficacy was determined for the target parasite by calculating the percent efficacy as 100 $[(C-T) / C]$, where $C$ was the geometric mean among controls, and $T$ was the geometric mean among the treated animals. The log-counts of both groups were compared using an F-test adjusted for the allocation blocks used to randomize the animals to the treatment groups (Studies 2-5). The MIXED procedure in SAS was used for the analysis, with the treatment groups listed as a fixed effect and the allocation blocks listed as a random effect. For Study 1 the log-counts of both groups were compared using the GLM Procedure in SAS. All testing was two-sided at the significance level $\alpha=0.05$.

\section{Results}

No adverse events or other health problems related to treatment with NexGard ${ }^{\circledR}$ Combo were observed throughout the studies.
The results (parasite counts, percentage efficacy, statistical comparison of treatment groups) of the five studies for the target parasites are summarized in Table 3. Cats treated with NexGard ${ }^{\circledR}$ Combo had significantly fewer adult $T$. cati ascarids and $D$. caninum tapeworms than the placebo-treated controls. In the individual studies, the percentage efficacies against adult T. cati were $98.8 \%$ and $100 \%$, and against D. caninum were $93.2 \%, 98.0 \%$ and $98.3 \%$. All studies were considered to have adequate challenge based on target parasite infections in the cats of at least five adult $T$. cati or at least two D. caninum recovered from a minimum of six cats of the respective placebo-treated control groups.

Inoculation with approximately 100 larvated $T$. cati eggs per cat in Study 1 resulted in the recovery of 319 adult $T$. cati in the placebo-treated controls, indicating a mean rate of establishment of $31.9 \%$.

In the three studies using naturally infected animals, nontarget parasites were recovered from one to nine cats in the placebo-treated control groups, including adult Ancylostoma tubaeforme (Studies 2 and 4), fourth-stage T. cati (Study 2), adult $T$. cati (Studies 4 and 5), dipylidiid cestodes (D. caninum, Diplopylidium spp. and Joyeuxiella pasqualei; Studies 2 and 4) and/or Taenia taeniaeformis (Study 5). However, the number of parasites recovered was not considered meaningful for efficacy calculations because the presence of patent infection with these parasites had not been demonstrated prior to treatment in a minimum of six cats in each of the treatment groups (Table 2).

\section{Discussion}

The results of the present studies testing the efficacy of the novel topical product NexGard ${ }^{\circledR}$ Combo administered to cats demonstrate that eprinomectin and praziquantel in combination 
with esafoxolaner provide high efficacy against adult $T$. cati and D. caninum infections. One administration of NexGard ${ }^{\circledR}$ Combo at the minimum label dose resulted in greater than 98\% reduction of adult $T$. cati ascarid burden, and greater than $93 \%$ reduction of $D$. caninum tapeworm burden.

These results are consistent with the level of efficacy in a series of controlled studies assessing treatment with Broadline $^{\mathrm{TM}}$, which delivers the same eprinomectin and praziquantel dosage as NexGard ${ }^{\circledR}$ Combo. These studies on experimentally and naturally infected cats demonstrated efficacy against adult $T$. cati and $D$. caninum ranging from $97.1 \%$ to $100 \%$ and $97.7 \%$ to $99.2 \%$, respectively [19, 20]. Results of the controlled laboratory Broadline ${ }^{\mathrm{TM}}$ studies were also supported in a multi-center field efficacy study demonstrating $99.9 \%$ and $100 \%$ efficacy against $T$. cati and D. caninum, respectively, based on results of examination of feces [32]. Equivalence of efficacy (100\%) for the praziquantel component delivered by the treatment of cats with the minimum label dose of Broadline ${ }^{\mathrm{TM}}$ and NexGard ${ }^{\circledR}$ Combo was also demonstrated against Echinococcus multilocularis cestode infections [30, 35]. The results of the present studies demonstrate the biologically equivalent anthelmintic efficacy against three parasites of both eprinomectin and praziquantel in NexGard ${ }^{\circledR}$ Combo and Broadline $^{\mathrm{TM}}$. The effect of these compounds is not impacted by the presence of the isoxazoline compound esafoxolaner in the formulation, resulting in eprinomectin and praziquantel plasma profiles that are considered to be similar to those of the above products [16].

The mode of inoculation in studies that involved experimentally infected cats performed well. The counts of adult T. cati recovered from the placebo-treated control cats in Study 1 provide further support for experimental regimens using lower doses of larvated eggs over two to three consecutive days, rather than a single larger dose at once, as previously recommended [20]. The rate of establishment and numbers of D. caninum in the placebo-treated control cats in Study 3 confirmed the suitability of the inoculation model, as previously described $[3,4,13]$. The spectrum of helminths recovered from the placebo-treated cats in the studies with naturally infected animals (Studies 2, 4 and 5) confirms their presence in domestic cats in the countries where the studies were conducted $[6,15]$ and re-emphasises the multi-species nature of feline intestinal parasitism. Diagnosis of cestode infections in cats requires special attention and may not be successful using routine methods. None of the cats in Study 2 were found to shed fecal forms of dipylidiid cestodes at a single fecal examination prior to treatment. However, 9 out of 10 placebo control cats were found with specimens of D. caninum. This supports the hypothesis that cestode infections are largely underestimated in cats [27].

The equivalent levels of efficacy demonstrated against adult $T$. cati and $D$. caninum, which were considered the least sensitive nematode and cestode species for eprinomectin and praziquantel, respectively, may reasonably allow to conclude that the administration of NexGard ${ }^{\circledR}$ Combo to cats will provide the same range of activity as does the administration of Broadline $^{\mathrm{TM}}$ with respect to nematode and cestode infections. Thus, the spectrum of activity of NexGard ${ }^{\circledR}$ Combo in cats may comprise migrating and intestinal larval $T$. cati, adult
Toxascaris leonina, adult and fourth-stage A. braziliense, A. ceylanicum and A. tubaeforme hookworms, adult and larval Aelurostrongylus abstrusus and Troglostrongylus brevior lungworms, vesical and pulmonary Capillaria ( $C$. plica, C. aerophila) and Diplopylidium spp., and J. pasqualei and T. taeniaeformis cestodes [19-26, 31-33] in addition to adult T. cati, D. caninum and E. multilocularis.

\section{Conclusion}

The results of the present series of studies demonstrated that NexGard $^{\circledR}$ Combo is safe and highly effective against experimentally induced and naturally acquired infections with adult $T$. cati ascarids and $D$. caninum tapeworms in cats. The product can therefore be assumed to provide efficacious and convenient treatment against a broad range of intestinal nematodes and cestodes parasitizing domestic cats worldwide.

Acknowledgements. The authors gratefully acknowledge the staff of contributing contract research organizations for conducting these studies to a high professional standard and Hailun Wang and Stephen Yoon, both Boehringer-Ingelheim Animal Health, for the statistical analyses of the data.

\section{Competing interest}

The work reported herein was funded by BoehringerIngelheim Animal Health. The authors are current employees of Boehringer-Ingelheim or external contractors. Other than that, the authors declare no conflict of interest. This document is provided for scientific purposes only. Any reference to a brand or trademark herein is for information purposes only and is not intended for any commercial purposes or to dilute the rights of the respective owners of the brand(s) or trademark(s). Broadline ${ }^{\mathrm{TM}}$, Centragard ${ }^{\circledR}$ and NexGard ${ }^{\circledR}$ are registered trademarks of Boehringer-Ingelheim Group.

\section{References}

1. AVMA. 2013. AVMA guidelines for the euthanasia of animals. 2013 Ed. Available at: https://www.avma.org/sites/default/files/ resources/euthanasia.pdf. Accessed Dec 7, 2020.

2. Becker AC, Rohen M, Epe C, Schnieder T. 2012. Prevalence of endoparasites in stray and fostered dogs and cats in Northern Germany. Parasitology Research, 111, 849-857.

3. Beugnet F, Delport P, Luus H, Crafford D, Fourie J. 2013. Preventive efficacy of Frontline ${ }^{\circledR}$ Combo and Certifect ${ }^{\circledR}$ against Dipylidium caninum infestation of cats and dogs using a natural flea (Ctenocephalides felis) infestation model. Parasite, 20, 7.

4. Beugnet F, Labuschagne M, de Vos C, Crafford D, Fourie J. 2018. Analysis of Dipylidium caninum tapeworms from dogs and cats, or their respective fleas - Part 2. Distinct canine and feline host association with two different Dipylidium caninum genotypes. Parasite, 25, 31.

5. Bowman DD, Hendrix CH, Lindsay DS, Barr SC. 2002. Feline clinical parasitology. Ames: Iowa State University Press.

6. Cantó GJ, Guerrero RI, Olvera-Ramírez AM, Milián F, Mosqueda J, Aguilar-Tipacamú G. 2013. Prevalence of fleas and gastrointestinal parasites in free-roaming cats in central Mexico. PloS One, 8, e60744. 
7. Capári B, Hamel D, Visser M, Winter R, Pfister K, Rehbein S. 2013. Parasitic infections of domestic cats, Felis catus, in western Hungary. Veterinary Parasitology, 192, 33-42.

8. Chai JY. 2013. Praziquantel treatment in trematode and cestode infections: an update. Infection and Chemotherapy, 45, 32-43.

9. Dantas-Torres F, Otranto D. 2014. Dogs, cats, parasites, and humans in Brazil: opening the black box. Parasites \& Vectors, $7,22$.

10. Deplazes P, van Knapen F, Schweiger A, Overgaauw PA. 2011. Role of pet dogs and cats in the transmission of helminthic zoonoses in Europe, with a focus on echinococcosis and toxocarosis. Veterinary Parasitology, 182, 41-53.

11. European Scientific Counsel Companion Animal Parasite. 2020. Worm control in dogs and cats. ESCCAP Guideline 01 Sixth Edition, https://www.esccap.org/uploads/docs/2fe4poh6_0778_ ESCCAP_Guideline_GL1_v10_1p.pdf.

12. Fisher M. 2003. Toxocara cati: an underestimated zoonotic agent. Trends in Parasitology, 19(4), 167-170.

13. Fourie JJ, Crafford D, Horak IG, Stanneck D. 2012. Prophylactic treatment of flea-infested cats with an imidacloprid/ flumethrin collar to forestall infection with Dipylidium caninum. Parasites \& Vectors, 5, 151.

14. Hogan CA, Schwenk H. 2019. Dipylidium caninum Infection. New England Journal of Medicine, 380.

15. Jacobs DE, Arakawa A, Courtney CH, Gemmell MA, McCall JW, Myers GH, Vanparijs O. 1994. World Association for the Advancement of Veterinary Parasitology (W.A.A.V.P.) guidelines for evaluating the efficacy of anthelmintics for dogs and cats. Veterinary Parasitology, 52, 179-202.

16. Jacquot V, Buellet P, Letendre L, Tong W, Li H, Tielemans E. 2021. Pharmacokinetics a novel endectoparasiticide topical formulation for cats, combining esafoxolaner, eprinomectin and praziquantel. Parasite, 28, 19.

17. Jerhold RW, Jessup DA. 2013. Zoonotic diseases associated with free-roaming cats. Zoonoses Public Health, 60, 189-195.

18. Jiang $P$, Zhang $X$, Liu RD, Wang ZQ, Cui J. 2017. A human case of zoonotic dog tapeworm, Dipylidium caninum (Eucestoda: Dilepidiidae), in China. Korean Journal of Parasitology, 55, 61-64.

19. Knaus M, Abu-Madi M, Ibarra-Velarde F, Kok D, Kusi I, Postoli R, Chester T, Rosentel J, Alva R, Irwin J, Visser M, Winter R, Rehbein S. 2014. Efficacy of a novel topical fipronil, (S)-methoprene, eprinomectin and praziquantel combination against naturally acquired intestinal nematode and cestode infections in cats. Veterinary Parasitology, 202, 18-25.

20. Knaus M, Baker C, Reinemeyer C, Chester T, Rosentel J, Rehbein S. 2014. Efficacy of a novel topical combination of fipronil,(S)-methoprene, eprinomectin and praziquantel against adult and larval stages of Toxocara cati in cats. Veterinary Parasitology, 202, 34-39.

21. Knaus M, Chester T, Rosentel J, Kühnert A, Rehbein S. 2014. Efficacy of a novel topical combination of fipronil, (S)methoprene, eprinomectin and praziquantel against larval and adult stages of the cat lungworm, Aelurostrongylus abstrusus. Veterinary Parasitology, 202, 64-68.

22. Knaus M, Chester T, Rosentel J, Visser M, Rehbein S. 2014. Efficacy of a novel topical combination of fipronil,(S)methoprene, eprinomectin and praziquantel against experimental infections of Toxascaris leonina in cats. Veterinary Parasitology, 202, 40-44.

23. Knaus M, Shukullari E, Rapti D, Rehbein S. 2015. Efficacy of Broadline against Capillaria aerophila lungworm infection in cats. Parasitology Research, 114, 1971-1975.
24. Knaus M, Shukullari E, Rosentel J, Rehbein S. 2014. Efficacy of a novel topical combination of fipronil, (S)-methoprene, eprinomectin and praziquantel against feline urinary bladder worm (Capillaria plica) infection. Veterinary Parasitology, 202, 45-48.

25. Knaus $M$, Taweethavonsawat $P$, Cheesman $T$, Visser $M$, Rehbein S. 2020. Efficacy of Broadline ${ }^{\circledR}$ in cats against induced infections with developing fourth-stage larval and adult Ancylostoma ceylanicum hookworms. Veterinary Parasitology: X, 3, 100025.

26. Knaus M, Visser M, Mayr S, Rehbein S. 2020. Efficacy of a topical combination of eprinomectin, praziquantel, fipronil and (S)-methoprene against developing and adult Troglostrongylus brevior lungworms (Nematoda, Crenosomatidae) in cats. Veterinary Parasitology: X, 4.

27. Little S, Adolph C, Downie K, Snider T, Reichard M. 2015. High prevalence of covert infection with gastrointestinal helminths in cats. Journal of the American Animal Hospital Association, 51, 359-364.

28. Lucio-Forster A, Bowman D. 2011. Prevalence of fecal-borne parasites detected by centrifugal flotation in feline samples from two shelters in upstate New York. Journal of Feline Medicine and Surgery, 13, 300-303.

29. Nagamori Y, Payton ME, Duncan-Decocq R, Johnson EM. 2018. Fecal survey of parasites in free-roaming cats in northcentral Oklahoma, United States. Veterinary Parasitology Regional Studies and Reports, 14, 50-53.

30. Prullage J, Bowman D, Ulrich M, Tielemans E. 2021. Efficacy of a novel topical combination of esafoxolaner, eprinomectin and praziquantel against Echinococcus multilocularis in cats. Parasite, 28, 29.

31. Prullage J, Knaus M, Bowman D, Chester ST, Visser M, Rehbein S, Rosentel J. 2014. Efficacy of a novel topical combination of fipronil, (S)-methoprene, eprinomectin and praziquantel against induced infections of Ancylostoma spp. nematodes of cats. Veterinary Parasitology, 202, 30-33.

32. Rehbein S, Capári B, Duscher G, Keidane D, Kirkova Z, Petkevicius S, Rapti D, Wagner A, Wagner T, Theodore Chester S, Rosentel J, Tielemans E, Visser M, Winter R, Kley K, Knaus M. 2014. Efficacy against nematode and cestode infections and safety of a novel topical fipronil, (S)-methoprene, eprinomectin and praziquantel combination product in domestic cats under field conditions in Europe. Veterinary Parasitology, 202, 10-17.

33. Schuster R, Mustafa MB, Baskar JV, Rosentel J, Chester T, Knaus M. 2016. Efficacy of a topical combination of fipronil, (S)-methoprene, eprinomectin and praziquantel $\left(\right.$ Broadline ${ }^{\circledR}$ ) against naturally acquired infections with cestodes of the genus Joyeuxiella in cats. Parasitological Research, 115, 2679-2684.

34. Symeonidou I, Gelasakis AI, Arsenopoulos K, Angelou A, Beugnet F, Papadopoulos E. 2018. Feline gastrointestinal parasitism in Greece: emergent zoonotic species and associated risk factors. Parasites \& Vectors, 11, 227.

35. Tielemans E, Manavella C, Visser M, Chester T, Rosentel J. 2014. Efficacy in cats of a novel topical combination of fipronil, (S)-methoprene, eprinomectin, praziquantel, against induced infestations of Echinococcus multilocularis. Veterinary Parasitology, 202, 26-29.

36. Traversa D. 2012. Pet roundworms and hookworms: a continuing need for global worming. Parasites \& Vectors, 5, 91-110.

37. Vercruysse J, Holdsworth P, Letonja T, Barth D, Conder G, Hamamoto K, Okano K. 2001. International harmonisation of Anthelmintic Efficacy Guidelines. Veterinary Parasitology, 96, 171-193. 
38. Vercruysse J, Holdsworth P, Letonja T, Conder G, Hamamoto K, Okano K, Rehbein S. 2002. International harmonisation of Anthelmintic Efficacy Guidelines (Part 2). Veterinary Parasitology, 103, 277-297.
39. Zottler EM, Bieri M, Basso W, Schnyder M. 2019. Intestinal parasites and lungworms in stray, shelter and privately owned cats of Switzerland. Parasitology International, 69, 75-81.

Cite this article as: Knaus M, Baker C, Alva R, Mitchell E, Irwin J, Shukullari E, Veliu A, Ibarra-Velarde F, Liebenberg J, Reinemeyer C, Tielemans E, Wakeland K \& Johnson C. 2021. Efficacy of a novel topical combination of esafoxolaner, eprinomectin and praziquantel in cats against Toxocara cati and Dipylidium caninum. Parasite 28, 28.

\section{(0) PARASTE}

An international open-access, peer-reviewed, online journal publishing high quality papers on all aspects of human and animal parasitology

Reviews, articles and short notes may be submitted. Fields include, but are not limited to: general, medical and veterinary parasitology; morphology, including ultrastructure; parasite systematics, including entomology, acarology, helminthology and protistology, and molecular analyses; molecular biology and biochemistry; immunology of parasitic diseases; host-parasite relationships; ecology and life history of parasites; epidemiology; therapeutics; new diagnostic tools.

All papers in Parasite are published in English. Manuscripts should have a broad interest and must not have been published or submitted elsewhere. No limit is imposed on the length of manuscripts.

Parasite (open-access) continues Parasite (print and online editions, 1994-2012) and Annales de Parasitologie Humaine et Comparée (1923-1993) and is the official journal of the Société Française de Parasitologie. 